\title{
Imatinib mesylate treatment in a dog with gastrointestinal stromal tumors with a c-kit mutation
}

\author{
Mitsuhiro IRIE ${ }^{1) *}$, Yoshinori TAKEUCHI ${ }^{2)}$ Yuzo OHTAKE$^{1)}$, Hitomi SUZUKI ${ }^{1)}$, Nao NAGATA ${ }^{1)}$, Takuma MIYOSHI ${ }^{1)}$, \\ Yumiko KAGAWA ${ }^{3)}$ and Tetsushi YAMAGAMI ${ }^{3)}$ \\ ${ }^{1)}$ Shikoku Veterinary Medical Center, 3308-5 Ikenobe, Miki-cho, Kita-gun, Kagawa 761-0701, Japan \\ ${ }^{2)}$ Department of Veterinary Internal Medicine, Graduate School of Agricultural and Life Sciences, The University of Tokyo, 1-1-1 Yayoi, \\ Bunkyo-ku, Tokyo 113-8657, Japan \\ ${ }^{3)}$ North Labo, 8-35 2-chome-kita, Hongo, Shiroishi-ku, Sapporo-shi, Hokkaido 003-0027, Japan
}

(Received 16 February 2015/Accepted 1 June 2015/Published online in J-STAGE 12 June 2015)

ABSTRACT. A 13-year-old spayed mixed-breed dog was diagnosed with a gastrointestinal stromal tumor (GIST) after histopathological examination of an abdominal mass. Five months after surgical resection of the tumor, we detected the recurrence of GIST with multiple disseminated abdominal lesions. A sequence analysis of cDNA obtained from a biopsy of the recurrent tumors revealed a mutation within exon 9 of the c-kit gene (1523A>T, Asn $\left.{ }^{508} \mathrm{Ile}\right)$, which has been shown to cause ligand-independent phosphorylation of the KIT protein in GISTs and canine mast cell tumors (MCTs). Upon detection of the recurrent tumors, we initiated treatment with imatinib mesylate (10 mg/ $\mathrm{kg}$, q $24 \mathrm{hr}$ ). After 2 months, the dog achieved complete remission. Our findings indicate that canine GIST, and possibly MCT, may be responsive to molecular-targeted therapy.

KEY WORDS: canine, gastrointestinal stromal tumor, imatinib mesylate

doi: 10.1292/jvms.15-0096; J. Vet. Med. Sci. 77(11): 1535-1539, 2015

Gastrointestinal stromal tumors (GISTs) occur in humans, dogs and other species, and are among the most common mesenchymal tumors that originate from the interstitial cells of Cajal in the walls of the gastrointestinal tract $[14,15]$.

The c-kit gene encodes the KIT protein, which is a receptor tyrosine kinase that mediates the signaling of stem cell factor (SCF), a cytokine involved in hematopoiesis and mast cell growth [12].Mutations of the c-kit gene have been identified in exons $9(5-10 \%)$ and $11(60-70 \%)$ in cases of human GISTs [1]. Studies on human GISTs [3] and canine mast cell tumors (MCTs) [7] have indicated that imatinib mesylate, a tyrosine kinase inhibitor, may be effective in the treatment of these tumors, depending on the presence and location of c-kit mutations [6,9]. Furthermore, a previous case study has reported imatinib mesylate to be effective against canine GISTs that contained a mutation in exon 11 of the c-kit gene [9]. Cases of canine GISTs with c-kit mutations may therefore be clinically responsive to imatinib mesylate treatment $[5,6]$.

Here, we describe a case of canine recurrent GIST harboring a mutation in exon 9 of the c-kit gene that responded clinically to the administration of imatinib mesylate.

A 13-year-old, 10-kg, spayed mixed-breed dog with a body condition score of $3 / 5$ and a 1 -week history of vomiting and anorexia was referred to the Shikoku Veterinary Medical

*Correspondence to: Irie, M., Shikoku Veterinary Medical Center, 3308-5 Ikenobe, Miki-cho, Kita-gun, Kagawa 761-0701, Japan. e-mail:mac@vet.ne.jp

(C)2015 The Japanese Society of Veterinary Science

This is an open-access article distributed under the terms of the Creative Commons Attribution Non-Commercial No Derivatives (by-nc-nd) License $<$ http://creativecommons.org/licenses/by-nc-nd/3.0/>.
Center, located in Kagawa Prefecture, Japan. Upon physical examination, we detected a large mass in the abdominal cavity through palpation. Abdominal ultrasonography revealed the mass to be approximately $10 \mathrm{~cm}$ in diameter with mixed echogenicity. A fine-needle aspiration of the mass showed clusters of spindle-shaped cells. There were no apparent abnormalities observed in the complete blood cell count, blood chemistry tests or blood coagulation profile.

Abdominal radiography, however, revealed the presence of a single large lesion in the abdominal cavity. Based on computed tomography (CT) findings (Fig. 1A and 1B), we concluded that the mass originated from the cecum and could be surgically resected. Laparotomy exposed a tumor that was approximately $12 \times 8 \times 6 \mathrm{~cm}$ in size, had an irregular surface and originated from the cecum (Fig. 1C). In addition to the large mass, we observed 5 to 10 smaller masses (ranging from $1 \mathrm{~mm}$ to $20 \mathrm{~mm}$ in diameter) in the omentum. During surgery, the cecum was partially removed, and the omentum with the disseminated tumors was excised.

Histopathological examination of the excised tumor revealed that the mass had unclear boundaries and had originated from the muscle layer of the cecum. The tumor tissue was composed of spindle-form neoplastic cells arranged in streams and interlacing bundles, and was supported by abundant basophilic myxoid stroma. The tumor cells had wispy eosinophilic cytoplasm, as well as ovoid to cigar-shaped nuclei with a single small nucleolus (Fig. 2A). Mild to moderate anisocytosis and anisokaryosis were also observed in the tumor cells. The mitotic index ranged from 0 to 1 mitotic figures per 5 high-power fields (Fig. 2B).

Immunohistochemical analysis using an antibody against human KIT (Dako, Carpinteria, CA, U.S.A.) demonstrated that most of the tumor cells were positive for KIT proteins 


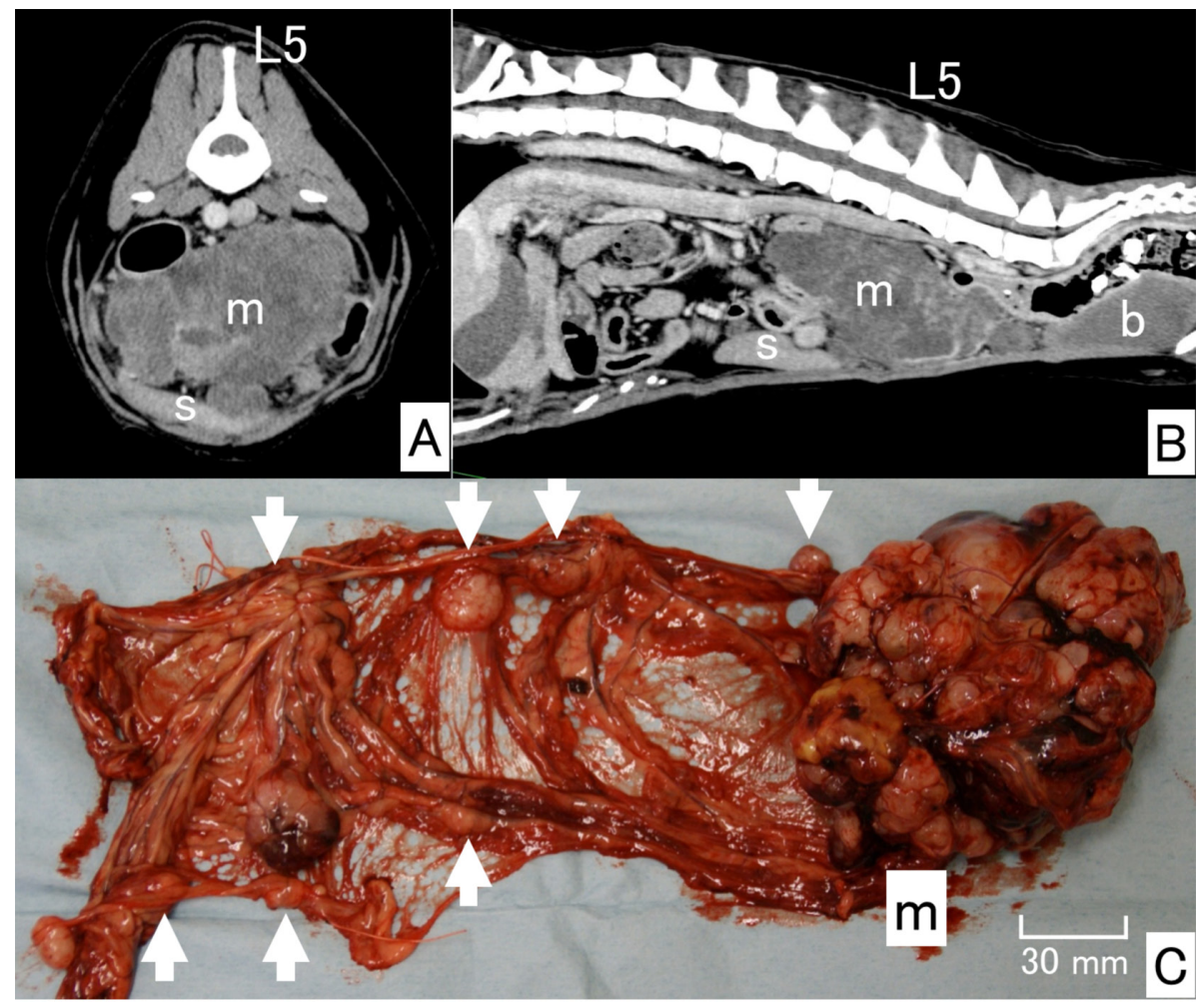

Fig. 1. Preoperative CT images: (A) Transverse image of the 5th lumbar vertebra and (B) sagittal image indicating a large mass with an irregular surface $(12 \times 8 \times 6 \mathrm{~cm}$ in size $)$ extending from the cecum. (C) Photograph of the surgically resected area showing the main tumor and multiple disseminated masses (arrows) in the omentum. L5, 5th lumbar vertebra; m, main tumor; s, spleen; b, bladder.
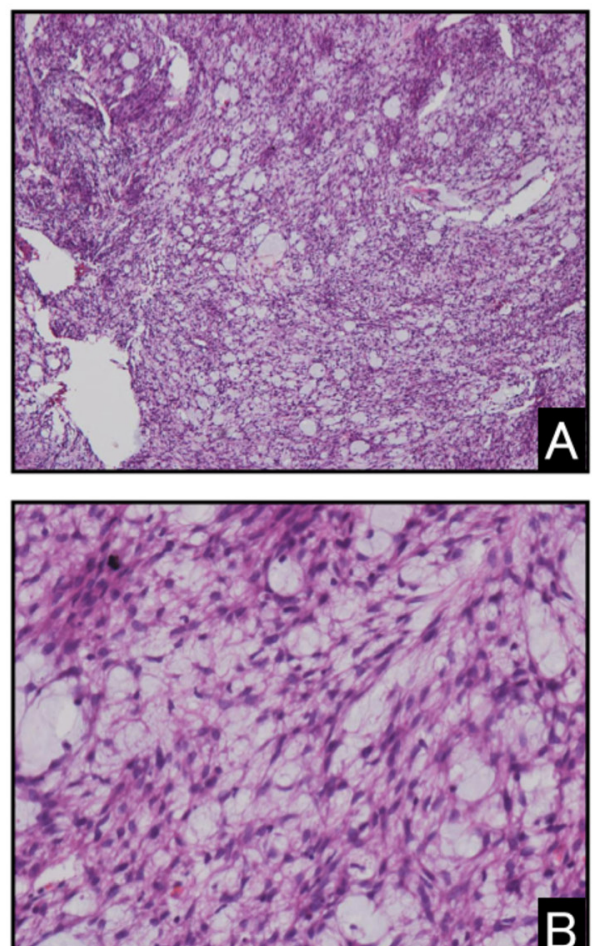

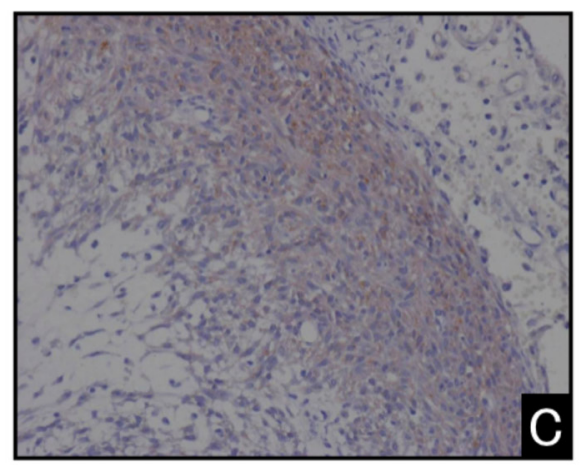

Fig. 2. (A) Histopathological features of the resected abdominal mass using hematoxylin and eosin stain at 100 $\times$ magnification. Tumors were composed of spindle-form neoplastic cells arranged in streams and interlacing bundles and were supported by abundant basophilic myxoid stroma. (B) Histopathological features of the resected abdominal mass using hematoxylin and eosin stain at $400 \times$ magnification. The tumor cells showed wispy eosinophilic cytoplasm, ovoid to cigar-shaped nuclei with a small single nucleolus, and mild to moderate anisocytosis and anisokaryosis. (C) Immunohistochemical analysis of the resected abdominal mass using immunohistochemical staining with anti-KIT antibodies followed by hematoxylin counterstain at $100 \times$ magnification. Most cells were positive for human KIT. 
(Fig. 2C), and the tumor was therefore identified as GIST. A DNA sample obtained from paraffin-embedded sections of the tumor was subjected to sequence analysis of exon 11 of the c-kit gene; however, no mutations were found in the target sequence.

Because several residual tumors were detected in the omentum, $200 \mathrm{mg} / \mathrm{m}^{2}$ of carboplatin (Paraplatin; BristolMyers Squibb, New York, NY, U.S.A.) was administered to the dog 2 weeks after surgery; the drug was further administered once every 3 weeks for a total of 6 doses. However, a scheduled follow-up examination conducted 160 days after the initial surgery indicated the possible recurrence of GIST in the omentum. CT scans showed the presence of numerous masses with diameters ranging from $2 \mathrm{~cm}$ to $5 \mathrm{~cm}$. Exploratory laparotomy revealed multiple tumors up to 5 $\mathrm{cm}$ in diameter. As the complete and safe removal of all the tumors was not feasible, only a limited number of masses were resected for biopsy. Histopathological examination of the resected masses confirmed the recurrence of GIST.

Total RNA was extracted from paraffin-embedded tumor tissue resected during the second surgery using an RNeasy FFPE kit (Qiagen, Valencia, CA, U.S.A.), and the corresponding cDNA was synthesized as previously described [16]. The forward primer 5'-GCACAGACACAGAGTAATAGC-3' and reverse primer 5'-GAAGGCACCAGCACCCAAAGT-3' were then used to amplify c-kit cDNA from the single-strand cDNA through PCR with KOD FX DNA polymerase (Toyobo, Osaka, Japan). The PCR products were sub-cloned into a pCR-Blunt vector (Invitrogen, Carlsbad, CA, U.S.A.), and the sequence of the full length c-kit cDNA was obtained using a previously described method [16]. When compared with the wild-type canine c-kit gene (GenBank accession no. AY313776), the GIST tissue showed a point mutation in exon 9 (1523A $>$ T) (Fig. 3).

Based on the findings of the c-kit sequence analysis, we began administration of imatinib mesylate $(10 \mathrm{mg} / \mathrm{kg} \mathrm{q}$ 24 hr) (Veenat; Natco Pharma, Hyderabad, India) 2 weeks after surgery. In an abdominal ultrasonography conducted 2 weeks after the initial imatinib mesylate administration, the lengths of the residual masses in the abdominal cavity were found to have shrunk to less than half of their original lengths. In accordance with the classification criteria for solid tumor response evaluation [4], the observed reduction in tumor size indicated a partial remission (PR). Two months after the initiation of imatinib mesylate treatment, ultrasonography and CT imaging indicated complete remission (CR) of GIST (Fig. 4). Treatment of imatinib mesylate with the same dosage was continued even after achievement of CR to prevent further recurrence. The dog remained in CR with continuous daily administration of imatinib mesylate. Ultrasonography was conducted during periodic health examinations once every 3-6 months.

Although the dog was periodically re-examined at our veterinary medical center, it eventually died of pneumonia 4 years and 5 months after the second surgery. There was no indication of GIST recurrence at the time of the dog's death.

This case did not present with any severe adverse events associated with imatinib mesylate treatment. All of the pro- cedures involved in the examination and treatment of this case were conducted in accordance with the guidelines for small animal practice issued by the Japanese Veterinary Medical Association in 2007.

A mutation within exon 9 of the c-kit gene $(1523 \mathrm{~A}>\mathrm{T})$ was found in the GIST tissue extracted from our canine patient. Although the phosphorylation of the KIT protein was not evaluated in this study, this type of mutation has been observed in $1.5 \%$ of canine MCTs [11] and has been shown to cause constitutive phosphorylation of the KIT protein [17].

The c-kit point mutation $(1523 \mathrm{~A}>\mathrm{T})$ observed in this case has yet to be reported in canine GISTs. Kobayashi et al. [9] have previously reported a case of canine GIST harboring a c-kit mutation in exon 11 that responded to imatinib mesylate treatment [8]; although imatinib mesylate treatment was able to generate a PR response, CR could not be achieved in their canine patient. In contrast, the canine patient described here achieved CR with the same dose of imatinib mesylate $(10 \mathrm{mg} / \mathrm{kg} \mathrm{q} 24 \mathrm{hr}$ ) and survived for a long period after treatment without relapse. Although a further study is needed to produce definitive results, our findings in conjunction with the report by Kobayashi et al. [9] suggest the possible effectiveness of imatinib mesylate for the treatment of GISTs in dogs.

As human GIST patients with exon 9 or exon 11 mutations in the $c$-kit gene have been shown to be responsive to imatinib mesylate treatment [2], this has become the first-choice drug in the treatment of metastatic or recurrent GISTs. However, patients with exon 9 mutations have been reported to have decreased sensitivity to this treatment $[1,3]$. Therefore, such patients require higher doses of imatinib mesylate, or even treatment with other tyrosine kinase inhibitors, such as sunitinib malate. Despite having an exon 9 c-kit mutation, our canine patient demonstrated good response to imatinib mesylate treatment and was able to achieve CR. This apparent discrepancy may be explained in part by the difference in the type of exon 9 mutation between canine (point mutation) and human (duplication) GISTs. It has been documented that the responsiveness of human GISTs to anticancer drugs can be affected by differences in the types of c-kit mutations [1].

Although our canine patient remained in CR during the follow-up period, we decided to provide long-term administration of imatinib mesylate to prevent further recurrence. Several studies have suggested that the long-term administration of imatinib mesylate may lead to the emergence of drug-resistant clones in the treatment of advanced GISTs in humans $[1,8,13]$. On the other hand, Le Cesne et al. have advocated non-interrupted imatinib mesylate treatment for advanced human GISTs unless adverse effects are evident [10]. As our patient did not develop any severe adverse events during the treatment, we decided to continue the administration of imatinib mesylate.

In this case study, the administration of imatinib mesylate was found to be an effective treatment in a canine patient with GISTs that contained an exon 9 mutation in the c-kit gene. Molecular-targeted therapy may therefore be a promising therapeutic strategy for GISTs in dogs. 


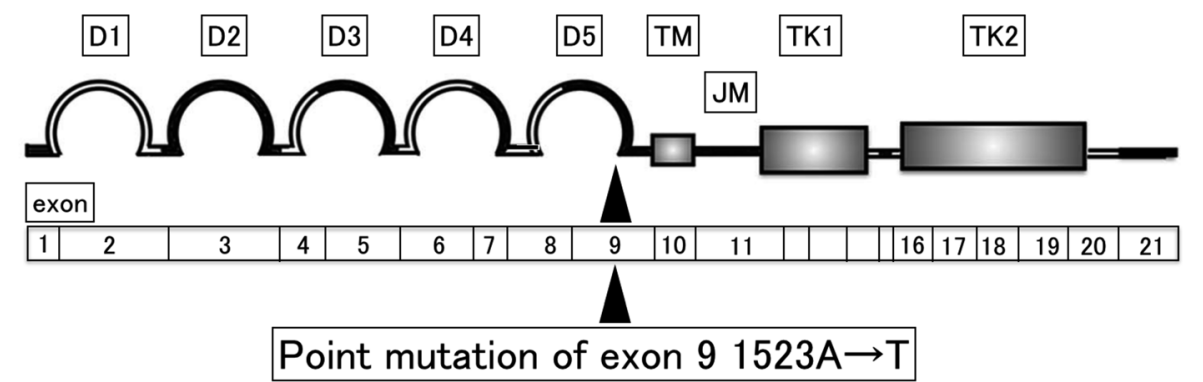

Ser Ser Ala Phe Phe IIe Phe Ala Phe Lys Glu
Wild Type AGT TCT GCC TTT TTT ATC TTT GCA TTT AAA GAA

Mutant Ser Ser Ala Phe Phe Asn Phe Ala Phe Lys Glu AGT TCT GCC TTT TTT AAC TTT GCA TTT AAA GAA

Fig. 3. Identification of the point mutation in the c-kit gene and assembly of wild-type and mutant c-kit nucleotide sequences. D1 to D5, immunoglobulin-like domains; TM, transmembrane domain; JM, juxtamembrane domain; TK1, adenosine triphosphate (ATP) binding site; TK2, activation loop.
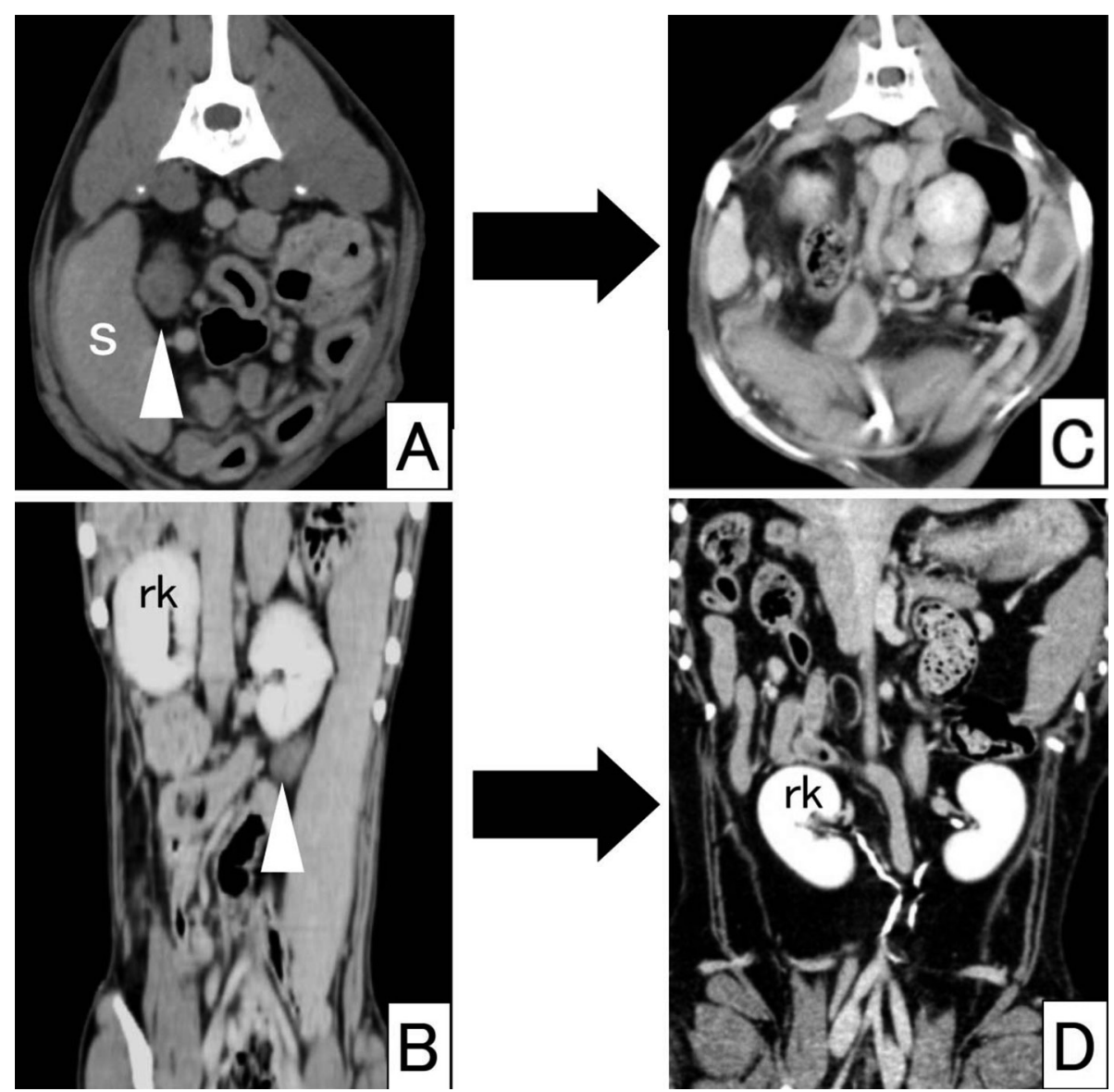

Fig. 4. CT images taken after the recurrence of GIST: (A) Transverse image and (B) frontal image of the abdomen taken 162 days after the initial surgery. The white arrowheads indicate the intraabdominal mass. (C) Transverse image and (D) frontal image of the abdomen taken 1,700 days after the initial surgery. The mass was observed to have completely disappeared in this later stage. s, spleen; rk, right kidney. 
ACKNOWLEDGMENTS. We would like to thank Professor Hajime Tsujimoto from the Department of Veterinary Internal Medicine, Graduate School of Agricultural and Life Sciences, The University of Tokyo, for his advice in the preparation of this manuscript. None of the authors have any financial relationships with individuals or organizations that could inappropriately influence or bias the content of the study.

\section{REFERENCES}

1. Corless, C. L., Barnett, C. M. and Heinrich, M. C. 2011. Gastrointestinal stromal tumours: origin and molecular oncology. Nat. Rev. Cancer 11: 865-878. [Medline]

2. Debiec-Rychter, M., Wasag, B., Stul, M., De Wever, I., Van Oosterom, A. and Hagemeijer, A. 2004. Gastrointestinal stromal tumours (GISTs) negative for KIT (CD117 antigen) immunoreactivity. J. Pathol. 202: 430-438. [Medline] [CrossRef]

3. de Silva, C. M. and Reid, R. 2003. Gastrointestinal stromal tumors(GIST): C-kit mutations, CD117 expression, differential diagnosis and targeted cancer therapy with imatinib. Pathol. Oncol. Res. 9: 13-19. [Medline] [CrossRef]

4. Eisenhauer, E. A., Therasse, P., Bogaerts, J., Schwartz, L. H., Sargent, D., Ford, R., Dancey, J., Arbuck, S., Gwyther, S., Mooner, M., Rubinstein, L., Shankar, L., Dodd, L., Kaplan, R., Lacombe, D. and Verwell, J. 2009. New response evaluation criteria in solid tumours: revised RECIST guideline (version 1.1). Eur. J. Cancer 45: 228-247. [Medline] [CrossRef]

5. Frost, D., Lasota, J. and Miettinen, M. 2003. Gastrointestinal stromal tumors and leiomyomas in the dog: a histopathologic, immunohistochemical, and molecular genetic study of 50 cases. Vet. Pathol. 40: 42-54. [Medline] [CrossRef]

6. Gregory-Bryson, E., Bartlett, E., Kiupel, M., Hayes, S. and Yuzbasiyan-Gurkan, V. 2010. Canine and human gastrointestinal stromal tumors display similar mutations in c-KIT exon 11 . BMC Cancer 10: 559. [Medline] [CrossRef]

7. Isotani, M., Ishida, N., Tominaga, M., Tamura, K., Yagihara, H., Ochi, S., Kato, R., Kobayashi, T., Fujita, M., Fujino, Y., Setoguchi, A., Ono, K., Washizu, T. and Bonkobara, M. 2008. Effect of tyrosine kinase inhibition by imatinib mesylate on mast cell tumors in dogs. J. Vet. Intern. Med. 22: 985-988. [Medline] [CrossRef]

8. Joensuu, H., Hohenberger, P. and Corless, C. L. 2013. Gastrointestinal stromal tumour. Lancet 382: 973-983. [Medline]
[CrossRef]

9. Kobayashi, M., Kuroki, S., Ito, K., Yasuda, A., Sawada, H., Ono, K., Washizu, T. and Bonkobara, M. 2013. Imatinib-associated tumour response in a dog with a non-resectable gastrointestinal stromal tumour harbouring a c-kit exon 11 deletion mutation. Vet. J. 198: 271-274. [Medline] [CrossRef]

10. Le Cesne, A., Ray-Coquard, I., Bui, B. N., Adenis, A., Rios, M., Bertucci, F., Chevreau, C., Cupissol, D., Cioffi, A., Chabaud, S., Perol, D., Blay J. Y., French Sarcoma Group 2010. Discontinuation of imatinib in patient with advanced gastrointestinal stromal tumours after 3 years of treatment: an open-label multicenter randomized phase 3 trial. Lancet Oncol. 11: 942-949. [Medline] [CrossRef]

11. Letard, S., Yang, Y., Hanssens, K., Palmerini, F., Leventhal, P. S., Guery, S., Moussy, A., Kinet, J. P., Hermine, O. and Dubreuil, P. 2008. Gain-of-function mutations in the extracellular domain of KIT are common in canine mast cell tumors. Mol. Cancer Res. 6: 1137-1145. [Medline] [CrossRef]

12. Li, S. Q., O’Leary, T. J., Sobin, L. H., Erozan, Y. S., Rosenthal, D. L. and Przygodzki, R. M. 2000. Analysis of KIT mutation and protein expression in fine needle aspirates of gastrointestinal stromal/smooth muscle tumors. Acta Cytol. 44: 981-986. [Medline] [CrossRef]

13. Nishida, T., Takahashi, T. and Miyazaki, Y. 2009. Gastrointestinal stromal tumor; a bridge between bench and bedside. Gastric Cancer 12: 175-188. [Medline] [CrossRef]

14. Russell, K. N., Mehler, S. J., Skorupski, K. A., Baez, J. L., Shofer, F. S. and Goldschmidt, M. H. 2007. Clinical and immunohistochemical differentiation of gastrointestinal stromal tumors from leiomyosarcomas in dogs: 42 cases (1990-2003). J. Am. Vet. Med. Assoc. 230: 1329-1333. [Medline] [CrossRef]

15. Sarlomo-Rikala, M. and Kovatich, A. J. 1998. CD117: a sensitive marker for gastrointestinal stromal tumors that is more specific than CD34. Mod. Pathol. 11: 728-734. [Medline]

16. Shirao, K., Nishida, T., Doi, T., Komatsu, Y., Muro, K., Li, Y., Ueda, E. and Ohtsu, A. 2010. Phase I/II study of sunitinib malate in Japanese patients with gastrointestinal stromal tumor after failure of prior treatment with imatinib mesylate. Invest. New Drugs 28: 866-875. [Medline] [CrossRef]

17. Takeuchi, Y., Fujino, Y., Watanabe, M., Nakagawa, T., Ohno, K., Sasaki, N., Sugano, S. and Tsujimoto, H. 2010. Aberrant autophosphorylation of c-kit receptor in canine mast cell tumor cell lines. Vet. Immunol. Immunopathol. 137: 208-216. [Medline] [CrossRef] 